\title{
¿PARADIGMAS O PARADIGMATITIS? ACERCA \\ DE LOS INCONVENIENTES USOS \\ DE ESTE CONCEPTO EN LA EPISTEMOLOGÍA PSICOLÓGICA
}

\author{
PARADIGMS OR PARADIGMATITIS? ABOUT \\ THE INCONVENIENT USES \\ OF THIS CONCEPT IN THE PSYCHOLOGICAL EPISTEMOLOGY
}

\section{Armando Campos Santelices*}

\author{
Una idea entera se cambia porque una palabra se \\ trasladó de sitio, o porque otra se instaló como una \\ reinita en una frase que no la esperaba y que le obedeció. \\ Pablo Neruda. Memorias.
}

RESUMEN

Con base en una breve revisión acerca de los significados que le diera T.S. Kuhn a "paradigma", incluyendo diversas relaciones de sentido con otras ideas suyas, se concluye primero que estas ideas no son aplicables al desarrollo de la Psicología. En seguida, se propone la tesis principal del artículo, sin que esto se pueda interpretar como una influencia kuhniana: en nuestra disciplina se ha tornado influyente una paradigmatitis, la cual ocurre cuando la noción de "paradigma" se adopta para establecer fronteras infranqueables entre corrientes de pensamiento que en realidad se conectan dialécticamente, mediante diversas contradicciones, entrecruces y reemplazos.

PALABRAS CLAVE: PSICOLOGIA * PARADIGMA * EPISTEMOLOGÍA * ESCUELAS PSICOLOGICAS * KUHN

\section{ABSTRACT}

Based on a brief review of the meanings that T.S. Kuhn gave to the term "paradigm", along with various senses of its relationships with others of his ideas, it is concluded that these ideas are not pertinents to the development of Psychology. Then, it proposes the main thesis of this article, with the caveat that it is not Kuhn ideas that have not been an influence:

Profesor emérito de la Universidad de Costa Rica. Miembro del Colegio Profesional de Psicólogos de Costa Rica. ergosum.campos@gmail.com 
in our discipline, rather what has become influential is a paradigmatitis, a problem that occurs when the notion of paradigm is adopted in order to set inviolable limits between currents of thought which actually relate dialectically by several contradictions, crossovers and substitutions.

KEYWORDS: PSYCHOLOGY * PARADIGM * EPISTEMOLOGY * PSYCHOLOGICAL SCHOOLS * KUHN

\section{LIMINARES}

Según se desprende del decir y hacer de muchas personas vinculadas a la disciplina, el (auto) etiquetamiento "paradigmático" vendría a ser, en el quehacer psicológico, tan necesario como mostrar la cédula de identidad al cambiar un cheque en el banco.

Esta costumbre o creencia no deja de ganar adeptos y el término "paradigma", aunque teñido de connotaciones particulares, se ha incorporado ampliamente a la jerga del oficio. Tras su aparente inocencia, se suma a la vieja galería de "falsos problemas" epistemológicos y metodológicos que pertinazmente hemos alentado. El desdén por la teoría, los intentos por imponer un método único, la absurda oposición entre lo social y lo biológico, o entre lo cualitativo y lo cuantitativo, son tan solo algunos de los equívocos más graves dentro de una disciplina propensa a inseguridades innecesarias y carentes de fundamento. Problemas que nadan como ciertos habitantes del mar: a ratos se sumergen, nunca muy profundamente $y$ asoman a la superficie, una y otra vez, experimentando transformaciones que a veces no comprometen más que su aspecto externo.

Los esquemas de clasificación epistemológica que hoy se manejan bajo la noción de "paradigmas", tienen su antecedente más próximo y directo en la vieja diferenciación de "escuelas psicológicas", cuya función ordenadora, aunque fue encontrando crecientes dificultades en virtud de las ramificaciones y puntos de encuentro que se iban dando en su desenvolvimiento, operó en la Psicología occidental sin grandes turbulencias, en un clima de pacífica coexistencia, más o menos durante los dos primeros tercios del siglo pasado.
Tal estado del arte experimentó su más importante convulsión, por lo menos en América Latina, con el encuentro frontal "entre el conductismo y el psicoanálisis”, allá por los años 60 , cuyo examen resulta aún hoy muy sugerente.

Pero esta disputa no fue tan sencilla como podría sugerirlo la identificación gruesa de los contendientes. El choque principal, que salió en buena parte de la academia, ocurrió propiamente entre la terapia conductual y el psicoanálisis como método de tratamiento psicológico. Tal como lo precisa Mariano Yela $(1996)^{1}$, la primera tiene "claros precedentes en el conductismo" pero "ni empieza con él, ni se reduce a su aplicación".

Entonces, la virulencia del pleito tuvo que ver principalmente con la validez o eficacia de programas diferentes de trabajo clínico $y$ arrastró, por lo tanto, un fuerte trasfondo de intereses profesionales en competencia.

Otro choque, ciertamente relacionado con el anterior y más o menos paralelo en el tiempo, pero nunca idéntico, se escenificó principalmente en los círculos académicos. Se produjo cuando los heraldos de un conductismo en declive (Yela, 1996) ${ }^{2}$, fieles al "objetivismo antimentalista" de

$1 \quad$ Este autor se refiere al conductismo como el "intento más ambicioso y tenaz de la historia de la Psicología - y tal vez en toda la historia de la ciencia- de construir un sistema científico estrictamente lógico y objetivo".

2 En el trabajo precitado, Yela propone distinguir cinco fases en la evolución del conductismo: nacimiento y difusión (1910-1930), la era de las teorías (1930-1950), crisis (1950-1960), declive y caída. Describe esta última fase como una transformación, en el sentido de que la mayoría de los psicólogos que siguieron autodenominándose "conductistas", dejaron de entender la conducta como objeto 
sus primeros tiempos, punta de lanza del positivismo psicológico, se lanzaron agresivamente contra todo lo que se opusiera a ese principio $y$ a sus aplicaciones prácticas. Entre sus manifestaciones más tenaces, se destacaron dos: el reclamo de la "psicobiología" y de la "investigación cuantitativa" como dominios privativos para su enfoque y la descalificación del psicoanálisis en cualquiera de sus vertientes.

La intensidad de esta confrontación bifronte desplazó a un segundo plano otras divergencias y se convirtió en un factor clave para un cambio de estilo en los alegatos epistemológicos (o "cuasiepistemológicos"): se estrechó el margen para esa condescendencia descriptiva que hasta ese entonces caracterizaba a los análisis sobre las diversas escuelas psicológicas $^{3}$ y esto contribuyó poderosamente a desdibujar, al menos en apariencia, el apacible papel diferenciador que estas cumplían.

Sin embargo, el paulatino y nunca completo agotamiento de la noción de "escuela", no puso fin al hábito intelectual que la había sostenido: "canalizar la comunicación intradisciplinaria mediante el empleo de parcelaciones epistemológicas mutantes". Más bien, se reforzó al calor de las disputas que se agudizaban, lo que a su vez generó condiciones propicias para la instalación, en versiones aplanadas, de la noción de "paradigma".

En estas líneas se tratará de explicar por qué, tras su envoltura como buena costumbre o avance en el bien hablar, este concepto se ha difundido entre nosotros con significados que traen consigo severos peligros para el desarrollo teórico de la Psicología. Antes de comenzar este artículo se pensó en abordarlos directamente, sin ninguna clase de preámbulo epistemológico, porque tales significados, en rigor, no encuen-

único o principal de la investigación psicológica, para asumirla como una de las vías (en general, la fundamental) para la verificación de las hipótesis psicológicas.

3 Los avances logrados en la época por la psicología humanista, significativamente bautizada por Abraham Maslow como "tercera fuerza", abrieron un espacio epistemológico y profesional novedoso y una opción para muchos, pero no limaron las asperezas de un choque que, al fin y al cabo, contenía puntos de contradicción fundamentales. tran pleno respaldo en ninguno de los filósofos de la ciencia que han tratado el tema. Pero, ya que a menudo se considera que el pensamiento de Kuhn los apoya de manera contundente, se consideró inconveniente dejarlo de lado.

De este modo, en el recorrido que viene se tendrá en referencia dos contextos de sentido:

a) "paradigma" en su sentido etimológico, entendido como un "modelo, patrón o ejemplo". Empleado en múltiples áreas del conocimiento e incluso en la literatura religiosa, en nuestro terreno epistemológico connota la atribución de cualidades de verdad (o quizás de certeza) únicas o superiores a una determinada teoría o corriente de pensamiento. Sus adherentes la sustentarán, como se discutirá luego, con el carácter de una propuesta a seguir o argumentarán en pro de su dominio, aunque los recursos empleados para intentarlo variarán entre el debate tolerante $y$ las acciones, lamentablemente no raras en el concierto académico, directamente orientadas a quitarles espacio a "esos otros".

b) "paradigma" en el sentido que le imprimió el filósofo de la ciencia estadounidense Thomas Samuels Kuhn (19221996) y que ha de buscarse no solamente en su libro más conocido (La estructura de las revoluciones científicas ${ }^{4}$-1962) y en sus modificaciones, sino también en otros trabajos suyos ${ }^{5}$. Esto sin dejar de

4 Había aparecido anteriormente como monografía, en la Enciclopedia Internacional de la Ciencia Unificada, lo que permite reconocerle medio siglo. Más aún, Kuhn había presentado algunas de las ideas básicas de esta obra en otra anterior, $L a$ Revolución Copernicana, publicada en 1957.

5 Se han identificado más de veinte "definiciones" al respecto. En la "Postdata" de La estructura..., incorporada por el autor en la segunda edición en inglés (1969), ya aparecen precisiones que modifican el concepto. Otros hitos importantes en esta dirección son: su ensayo "Reflections on my critics", editado por Imre Lakatos y Alan Musgrave (Criticism and the growth of knowledge, 1970), en que procura eliminar "equívocos" sobre el tema. Más adelante, sus Segundos pensamientos sobre paradigmas $(1974,1977)$ en que aclara 
lado el hecho de que cualquier intento por entender con razonable precisión este concepto se enfrentará a las numerosas matizaciones y cambios que su autor le introduce a lo largo de su obra, en general intrincada $y$ susceptible de múltiples lecturas a causa de sus zigzagueos.

\section{THOMAS SAMUELS KHUN}

ACERCA DE LAS RELACIONES DE SU PENSAMIENTO CON LAS CIENCIAS SOCIALES

Los psicólogos y en general los científicos sociales, podemos remitirnos básicamente a Kuhn por dos vías: la primera tiene que ver con las relaciones específicas entre las ideas de este autor y la Psicología. La segunda podría centrarse en su enfoque "historicista" y en los rasgos "antipositivistas" de su pensamiento, particularmente su rechazo a "la necesidad de fundamentos universales tajantes" (Vázquez, Acevedo J. A., Manassero y Acevedo P., 2001) y ante los extremos "objetivistas" en el quehacer científico.

En lo que respecta a la primera vía, numerosos autores han resaltado el carácter bidireccional de estas relaciones o las han definido, como en el caso de Brunetti y Ormart, como "una trabazón substancial":

En su recorrido epistemológico, Kuhn transita por los más diversos modelos explicativos de la psicología ${ }^{6}$. A lo largo de su obra encontramos referencias a la

dos significados principales para el término $y$ refuta a quienes le atribuían ideas "relativistas" y "subjetivistas". Por último, la recopilación y publicación de los ensayos filosóficos que Kuhn elaboró entre 1970 y 1993, realizada por Conant y Haugeland en el año 2000, bajo el título The road since structure (disponible en español: El camino desde la estructura, 2002) resulta imprescindible para quien estudie su pensamiento.

6 Para cuidar el sentido de las ideas de estos autores, hay que agregar lo que ellos mismo apuntan: no se trata de un tránsito meramente exploratorio. Por ejemplo, el alejamiento que Kuhn lleva a cabo con respecto a la Gestalt $y$ su acercamiento a Piaget o a la psicología cognitiva, se funda para ellos en razones de fondo, que no cabe examinar aquí.
Gestalt, el asociacionismo, a Piaget y a la psicología cognitiva, intrincadas en un fértil diálogo con la generación del conocimiento científico (...) la investigación de Kuhn acerca de la historia de la ciencia lo ha conducido inevitablemente hacia el terreno de la psicología (2010).

Brunetti (2010), piensa que Kuhn, ya en La revolución copernicana (1957), le da un lugar de preeminencia a las "cuestiones cognitivas", al intuir que "en un cambio de esquema conceptual debía haber más que problemas estrictamente científicos" y al preguntarse "por el motivo que lleva a los sujetos a cambiar un esquema exitoso por otro". Asimismo, Fernando Gabucio (2002), para quien:

... es indudable que la interpretación del desarrollo científico propuesta por Kuhn ha tenido un enorme impacto... [que] alcanzó también a la reconstrucción histórica de la psicología (...). Es muy posible que debamos considerar a Kuhn como un miembro destacado e incluso precursor de la ciencia cognitiva, por el estilo con que él mismo había elaborado su concepción del devenir científico, apelando conjugadamente a nociones de historia de la ciencia, de sociología, de psicología y por supuesto filosóficas.

En esta misma dirección, resulta relevante ocuparse de los vínculos intelectuales que se entablaron entre Kuhn y el psicólogo suizo Jean Piaget, en cuyo análisis se suelen dejar de lado sus importantes diferencias.

En el capítulo IX de Psicogénesis e historia de la ciencia (1982), Piaget y García plantean al respecto un juicio de dos caras, que no deja lugar a dudas: reconocen, por una parte, que Kuhn "es indiscutiblemente un buen historiador de la ciencia" y se manifiestan a grandes rasgos de acuerdo con la caracterización que hace sobre ella ("largos períodos de ciencia normal con intervalos excepcionales de ciencia revolucionaria").

Pero, según lo declaran en seguida, "aquî también termina nuestro acuerdo: las implicaciones epistemológicas que extrae Kuhn son fundamentalmente distintas de las nuestras". 
Más adelante, refiriéndose a un análisis que Kuhn hace en Segundos pensamientos..., con el propósito de explicar como aprende un estudiante de ciencia sus "ejemplares", su crítica se torna aún más incisiva: "Curiosamente, Kuhn cae, en su análisis, en una posición de corte neopositivista... la misma que se empeñó en destruir".

En una perspectiva más amplia, la valoración que Kuhn hizo acerca del estatus científico de las ciencias sociales sigue siendo un tema problemático. Es muy cierto que frecuentemente caracteriza aspectos medulares de sus proposiciones como Psicología Social o como prefiere decir "Sociología", pero ¿significa esto que la considera una ciencia? Pues ya en el capítulo XIII de La Estructura..., esgrime un argumento aparentemente salomónico que le permite, a fin de cuentas, no pronunciarse sobre esta cuestión:

(...) hay hombres que pretenden que la psicología es una ciencia, debido a que posee tales o cuales características. Otros, al contrario, arguyen que esas características son innecesarias o que no son suficientes para convertir a ese campo en una ciencia.

Este relativismo bastaría por sí solo para entender que Kuhn tenía, por lo menos, serias dudas con respecto a la cientificidad de la Psicología. Pero el asunto no termina ahí: en el mismo capítulo que se citó, agrega sugerencias llenas de significado acerca de los criterios que esas personas emplearían para tomar partido en esa polémica. Por ahí "llega a sospechar" que la definición de ciencia no sería el criterio más importante, sino "algo más fundamental":

(...) ¿por qué no progresa mi campo del mismo modo que lo hace, por ejemplo, la física? ¿Qué cambios de técnicas, de métodos o de ideología lo harían capaz de progresar en esa forma?

Si vamos un poco más lejos, nos encontramos con un punto de mayor significado: a la hora de aplicar su concepto de paradigma $y$ de referirse a episodios "normales" o "revolu- cionarios" en la evolución de la ciencia, Kuhn emplea constantemente referencias interpretativas de carácter sociológico o psicológico, pero nunca dice que esos episodios se hayan producido alguna vez en estas disciplinas ni muestra ejemplo alguno sobre ello.

Podríamos suponer que Kuhn, en una prudente actitud, se atuvo a un viejo proverbio - "zapatero a tus zapatos" - y prefirió tomar sus abundantes ejemplos de revoluciones científicas de la Física, su profesión de base y en general de las ciencias "naturales". Pero, a mi juicio, esta conjetura se disuelve de una manera tal vez indirecta, pero contundente, cuando discurre acerca de las que denominó "ciencias" no maduras o preparadigmáticas.

Me referiré a esto más adelante, pero no quisiera pasar por alto, el llamado a la prudencia que nos hace Gabucio (2002, op. cit.) cuando arguye que la epistemología de Kuhn, "eminentemente descriptiva, no pretendía establecer la relación paradigma/madurez como un criterio de demarcación de la actividad científica". El hecho de que "la paradigmaticidad de la Psicología, entendida como criterio de cientificidad, haya impregnado tan frecuentemente la discusión, propicia sus usos abiertamente legitimadores". No obstante, "en uno de sus últimos escritos ${ }^{7}$, Kuhn juega con las mismas ideas, pero para concebirlas con menos rotundidad y certeza de la que muchos de sus usuarios les han atribuido".

Me parece exagerada la cautela que Garbucio aconseja. No sería apropiado darle demasiada importancia al tono supuestamente "tentativo, especulativo o vacilante" de los escritos del último Kuhn, sobre todo cuando se resalta que en estos se aclaran puntos fundamentales de su obra total. Esto traería consigo una irrespetuosa e innecesaria condescendencia.

\section{EL CONCEPTO KUHNIANO DE PARADIGMA Y SUS POSIBLES ALCANCES PARA LA PSICOLOGÍA}

Puede ser que la preocupación por este concepto, en nuestros círculos académicos, responda en muchos casos a un "efecto

$7 \quad$ Se refiere a Las ciencias naturales y humanas. Editorial Paidós, 2002. 
retroactivo". Es decir, que su adopción se haya producido, primero y por otras vías, como una moda lexicológica, para ser posteriormente conectada con el pensamiento de Kuhn para respaldar o negar la validez de un vocablo ya instalado en nuestra jerga.

Por otro lado, de ser cierto que en la epistemología psicológica prevalece el uso de paradigma como "modelo", posibilidad sugerida líneas atrás, no parecería relevante ocuparse aquí de los desarrollos que Kuhn le imprimió a esta noción.

No obstante, en ningún caso sería pertinente ignorar algo que salta a la vista: el pensamiento de este autor aparece continuamente en nuestros diálogos sobre el tema. Además, el ejercicio nos coloca ante diversos puntos relevantes para la epistemología psicológica. Veamos entonces: en el capítulo II de La estructura..., Kuhn se refiere a ciertos "libros clásicos y famosos de la ciencia" como obras que "sirvieron implícitamente, durante cierto tiempo, para definir los problemas y métodos legítimos de un campo de investigación para generaciones sucesivas de científicos".

Según arguye, tales obras pudieron hacer eso porque reunían dos características esenciales: i) “... carecían de precedentes suficientes como para haber podido atraer a un grupo duradero de partidarios, alejándolos de la competencia científica"; ii) "eran lo bastante incompletas para dejar muchos problemas para ser resueltos por el redelimitado grupo de científicos”. Concluye en que llamará "paradigmas", -de ahora en adelante- a las realizaciones que comparten estas dos características.

También en La estructura..., Kuhn nos proporciona una definición demasiado citada:

(los paradigmas son) realizaciones científicas universalmente reconocidas que, durante cierto tiempo, proporcionan modelos de problemas y soluciones a una comunidad científica.

Poco después (1969), en la "Posdata" que agrega a la obra mencionada, aclara que en ella se ha valido del término "paradigma" en dos sentidos distintos:
1) Como "toda la constelación de creencias, valores, técnicas etc., que comparten los miembros de una comunidad dada".

2) Como "una especie de elemento de tal constelación, las soluciones concretas de problemas que, empleadas como modelos o ejemplos, pueden reemplazar reglas explícitas como base de la solución de los restantes problemas de la ciencia normal" (cursivas propias).

Más adelante, Kuhn procura precisar sus primeras versiones de este concepto, mediante otro nuevo - "matriz disciplinar"- aunque sin desechar sus ideas básicas al respecto (según declaración propia). Básicamente, designó con este término un conjunto de elementos ordenadores - las generalizaciones simbólicas, los modelos, los "ejemplares" y los valores-, que se configuran como patrimonio común de quienes practican una disciplina particular.

Según la interpretación que se debe a Hilary Putnam (1985), un paradigma es para Kuhn una teoría que emerge acompañada por alguna aplicación "triunfal y sorprendente", la cual "mientras no sea objeto de refutaciones o falsaciones contundentes, se colocará como guía de las correspondientes actividades científicas".

Cabe preguntarse si en la Psicología se han dado alguna vez esa clase de "realizaciones". Pues un vistazo rápido sugeriría que eso fue lo que efectivamente ocurrió, en su momento, con el psicoanálisis, las terapias rogeriana y conductual, la psicología humanista, el modelo cognitivo-conductual y la vertiente lacaniana ${ }^{8}$, entre otros casos.

El lector juzgará si tales corrientes emergieron o no de manera "sorprendente", pero su carácter "triunfal" solo podría ser visto por sus más fervorosos adherentes, ya que ninguna de ellas logró expulsar a otras para instalarse dominante y solitaria.

$8 \quad$ En lo que respecta al psicoanálisis y a la vertiente lacaniana, no se recogerá aquí los argumentos relacionados con si "son o no psicología". Me limito a algo más simple para traerlas a colación: se enseñan en escuelas de psicología y por lo tanto, no están ausente en los debates epistemológicos que se realizan en ellas. 
En todo caso, insisto, el concepto kuhniano de paradigma no se llena de contenido sin ponerlo en relación con otros puntos clave. Tan solo en el marco de estas relaciones puede ser adecuadamente analizada su (in)aplicabilidad a la Psicología. Es lo que se intentará a continuación:

\section{1) "COMUNIDAD CIENTÍFICA"}

Este punto es particularmente relevante para comprender el significado que Kuhn le asigna a "paradigmas", precisamente porque nos dirá quiénes, según él, los toman como guías o pueden tomarlos.

El suspiro de alivio que un estudioso de Kuhn puede emitir al ver que este se interesó por explicar brevemente, en la "Posdata" a La estructura..., la "noción intuitiva" de comunidad científica que se encontraba "subyacente" en esta obra suya, rápidamente dará paso a la frustración: no hay uno sino varios significados del término, cómo no, $y$ por añadidura expuestos sin un orden que ayude a comprenderlos. A mi entender, estos significados son principalmente dos:

$\diamond \quad$ "Una comunidad científica consiste en quienes practican una especialidad científica"9. A lo cual añade: "las comunidades, desde luego, existen en muchos niveles. La más global es la comunidad de todos los científicos naturalistas (sic) ${ }^{10 "}$.

$\diamond \quad$ "En las ciencias hay escuelas, es decir, comunidades que enfocan el mismo tema desde puntos de vista incompatibles".

Que yo sepa, Kuhn no se propuso solucionar este acertijo, pero indirectamente se pronuncia a favor del primer significado, más adelante, al exponer su definición de "matriz disciplinar"1l.

$9 \quad$ Agrega que "es una idea que comparten extensamente científicos, sociólogos y numerosos historiadores de la ciencia...".

$10 \quad$ ¿Otra muestra del pobre estatus que le adjudica, si alguno, a las ciencias sociales?

11 Recordemos que este concepto amplía e incluye a "paradigma". No lo "reemplaza" como se suele afirmar.
En esta, se refiere a las comunidades científicas como colectividades que cultivan una misma disciplina.

En principio, esta doble definición arroja consecuencias interesantes para nuestra disciplina:

a) Si se toma su primer significado, se hace evidente la inaplicabilidad de "paradigmas", tanto a la producción de conocimiento sobre su historia como a su epistemología. La razón primordial, aunque no la única, es que evidentemente nunca ha habido un esquema mental, paradigma o matriz disciplinar común a todas las personas que "practican" la Psicología.

b) El segundo significado genera reflexiones que pueden enmarañarse: Kuhn dice "puntos de vista" y no "paradigmas", pero entonces, bueno habría sido que aclarase si esta definición — comunidades=escuelascoincidía o no con su concepto de paradigma. Nos da la tarea de rastrear en sus ideas y a mi juicio, la conclusión tiene que ser negativa. Entre otras razones, porque los paradigmas obviamente incluyen "puntos de vista”, pero son mucho más que eso.

\section{2) DESARROLLO HISTÓRICO DE LA CIENCIA}

Para Kuhn, la ciencia se mueve a lo largo de períodos transitorios de "ciencia normal", en que sus agentes (los individuos y comunidades que la cultivan) aprueban o sostienen, al menos mayoritariamente, determinados paradigmas nuevos. Mientras esta situación se prolongue, la ciencia tendrá un avance continuo, pero la acumulación de "anomalías" provocará situaciones de "crisis" que desembocan en un abandono del paradigma prevaleciente, esto es, en una "revolución científica". Como él mismo lo expresa en La estructura...:

(...) las revoluciones científicas se consideran aquí como aquellos episodios de desarrollo no acumulativo en que un antiguo paradigma es reemplazado, completamente o en parte, por otro nuevo e incompatible. 
De este modo, Kuhn plantea un punto clave de su pensamiento: "la discontinuidad de la ciencia". Muchos autores ven en este argumento su mayor diferencia con el positivismo.

Según Chalmers (2004), para Kuhn "un nuevo paradigma o un indicio para permitir una articulación posterior, surge repentinamente, a veces en medio de la noche, en la mente de un hombre sumergido profundamente en la crisis".

Pero no podríamos extrapolar este juicio $y$ entender que "discontinuidad paradigmática" significa para Kuhn el salto abrupto de un paradigma a otro, ya que se refiere repetidamente a "paradigmas rivales" y por supuesto, una idea no rivaliza con otra extinta.

Con "discontinuidad" quiere decir que esa irreconciliable rivalidad — que puede radicar en aspectos ontológicos, epistemológicos, conceptuales o perceptivos- cesará cuando un "paradigma" reemplace a otro(s) para instalarse como prevaleciente.

Bordeando lo obvio, hay que repetir que la Psicología nunca ha evolucionado de este modo. Cierto, coexisten en ellas tendencias de pensamiento rivales, que en su oposición suelen intercambiar calificativos muy drásticos. "Dogmatismo cientificista" y "no cientificidad" son tal vez los más lapidarios. Pero sin que una de ellas reemplace a todas las demás para establecer su reinado absoluto.

Por esta vía de análisis, se ha planteado que el esquema de Imre Lakatos podría ser más apropiado para nuestra disciplina, muy particularmente para dar cuenta de la transición del conductismo al cognitivismo en términos de "transición con continuidad" y no de "ruptura paradigmática" (Gabucio, 2002). Resulta interesante preguntarse acerca de si los fundamentos del modelo cognitivo conductual, tan influyente en la actualidad, comprueban ese esquema lakatosiano.

También contribuye a esa equivocada visión de ruptura y prevalencia paradigmática, una constante que se ha dado en la historia de la Psicología, que dicho sea de paso no "comienza como ciencia" con Wundt: los sostenedores de las grandes teorías o corrientes de pensamiento que coexisten en ella, suelen des- plegar "pretensiones paradigmáticas", entiéndase hegemónicas o excluyentes, e incluso llegan a pensar que son portadores $y$ voceros de un paradigma dominante (expresión redundante, por cierto). Pero pretender no es ser.

Por último, tal espejismo encuentra sustento en las situaciones que podríamos llamar "pseudo-paradigmáticas", caracterizadas por la aparente vigencia o predominio de un "paradigma" o la instalación de una "ciencia normal". Por ejemplo, hace unos treinta o cuarenta años, más o menos, casi la totalidad de la literatura especializada en Psicología general y social, que se usaba en las universidades latinoamericanas, procedía del funcionalismo norteamericano ${ }^{12}$. O en la antigua Unión Soviética, el materialismo dialéctico e histórico fue colocado, muy notoriamente durante el período estalinista, como la matriz oficial de las ciencias sociales.

Pero en ninguno de los dos casos hubo realmente una "ciencia normal" o un "dominio paradigmático": la hegemonía funcionalista constituyó una de las tantas expresiones de la dominación cultural que por entonces recaía intensamente sobre nuestra región y el intento por oficializar doctrinalmente el materialismo dialéctico fue una abierta negación del espíritu antidogmático que alienta al marxismo clásico.

Tampoco se produce una prevalencia paradigmática cuando en un país, los profesionales en Psicología se adhieren mayoritariamente a cierta corriente epistemológica, porque el peso de esa mayoría no clausurará sus diferencias.

Ahora bien, para las ciencias sociales, uno de los puntos más espinosos del pensamiento de Kuhn, radica en la distinción entre ciencias maduras y no maduras.

En su aplicación inicial de "paradigma"13, Kuhn planteó que hasta el siglo XVII, las teorías sobre la naturaleza de la luz se

12 Recuerdo que esta limitación determinó en nuestros círculos académicos una valoración especial del libro Psicología, ideología y ciencia, de Néstor Braunstein y colaboradores. Braunstein nos visitó años después como parte de su tarea de difundir el pensamiento lacaniano.

13 En la cual tiene en cuenta el desarrollo histórico de las grandes teorías y de las ciencias particulares. 
movían en un plano "preparadigmático" porque hasta entonces no se había aceptado una teoría unificada sobre este fenómeno y las que coexistían tenían que apoyarse en argumentos extracientíficos de distintas clases para man- tenerse en competencia. Posteriormente, irá más lejos: la carencia de un paradigma capaz de unificarla es propia de una "preciencia" o "ciencia inmadura".

Esquemáticamente, tendríamos:

\section{CIENCIA NO MADURA}

Preparadigmática: no prevalece un paradigma capaz de organizar u ordenar su desarrollo.

Hay un preconsenso (presencia simultánea de teorías rivales) y en virtud de ello no se producirá una pauta de avances científicos rápidos y consecuentes ${ }^{14}$.
CIENCIA MADURA

Paradigmática ${ }^{15}$ : prevalece un "paradigma".

Ciencia normal: "investigación basada firmemente en una o más realizaciones científicas pasadas, realizaciones que alguna comunidad científica particular reconoce, durante cierto tiempo, como fundamento para su práctica posterior"16.

Hay un consenso firme.
Por más que le doy vueltas al asunto, no encuentro elementos de clemencia en la condena que nos impone el pensamiento de Kuhn, aunque haya sido sin una intención directa ${ }^{17}$.

Condena comparable al mito de Sísifo: por años y años, los psicólogos habríamos trabajado bajo la ilusión de que hacemos ciencia. Empero, carentes de paradigmas y sin presentar intervalos de ciencia normal, la gran roca que empujamos hacia arriba se nos devolvería para depositarnos en el suelo desértico de una cruda verdad: ¡seríamos preparadigmáticos, cultores de una preciencia! ¿Qué le parece a usted?

\section{3) EL PRINCIPIO DE INCONMENSURABILIDAD/ INTRADUCIBILIDAD}

Según lo plantea Khun en La Estructura..., la relación entre los paradigmas que se suceden tras una revolución científica, como

14 Véase, de Thomas Kuhn (1977). La tensión esencial. México: Fondo de Cultura Económica, 1982.

El calificativo se ha empleado con otros significados. Por ejemplo, para algunos la Psicología "fue preparadigmática" mientras no logró separarse de la Filosofía.

Con este párrafo, Kuhn da inicio al Cap. II "El camino hacia la ciencia normal" de $L a$ Estructura...

$17 \quad 0$ al menos sin el tono categórico empleado por Wittgenstein y todavía más por Popper. alternativos o rivales, es "inconmensurable"18, por cuanto "no se reduce a novedad o incompatibilidad [incluye también] cambios de carácter léxico, en la forma de entender el mundo de la investigación y en los métodos, problemas y normas de solución que se aceptan".

Años más tarde, aplica este principio principalmente a las teorías y le otorga especial importancia a dos factores relacionados: las variaciones lingüístico-conceptuales y las formas de percibir o Gestalten (Lorenzano, 2008). Prepara así el terreno para su transformación "en una especie de intraducibilidad entre teorías, localizada en una u otra área en la que dos taxonomías léxicas difieren" (Kuhn, citado en Gabucio, 2002, op.cit. ${ }^{19}$ y que ocurre en ausencia de un lenguaje observacional neutral.

Tal como lo observa Gabucio (2002, op.cit.), de este cambio en el concepto de inconmensurabilidad se desprende que, a diferencia de lo planteado en La Estructura..., la comunicación entre miembros de comunidades científicas diferentes se hace posible dado que estos pueden "aprender o adquirir" las taxonomías léxicas de "la otra".

18 En su acepción original, tomada de las matemáticas, "inconmensurabilidad" se refiere a lo que no se puede medir en común.

19 
En el caso de la Psicología, resulta muy interesante preguntarse si la noción kuhniana de intraducibilidad es o no aplicable a ella. Esto en dos planos: en sus relaciones con otras disciplinas habitualmente conexas $y$ al interior de su propio cuerpo teórico.

Por razones epistemológicas y prácticas, la Psicología necesita involucrarse en nexos interdisciplinarios ${ }^{20}$. Pero esto no presupone que los psicólogos tengan que estar en capacidad de entender en toda su extensión, al trabajar juntos, el lenguaje utilizado por sus "no colegas". Solamente habrá intraducibilidad cuando no se logren construir las relaciones de sentido necesarias para pensar y actuar de manera integrada ${ }^{21}$.

A lo interno, en la Psicología funcionan, de una manera más o menos evidente, líneas temáticas diferenciadas que conviven en el binomio investigación-enseñanza y generan importantes fragmentaciones de un objeto de conocimiento difícilmente reconocible como "unitario". Por ejemplo, podríamos tener la justificada sospecha de que un psicólogo comunitario $y$ otro dedicado a la investigación en neurociencias "no tienen nada de qué hablar" (como psicólogos, claro está).

En el ámbito universitario y profesional, los distintos métodos o modelos de tratamiento psicológico se convierten a menudo en temas desconectados o en el mejor de los casos, se va perdiendo una buena costumbre: debatir acerca de su coexistencia. Por otra parte, la formación

20 Entendidos como la vinculación efectiva de diversos saberes, dentro de perspectivas y objetivos comunes que no necesariamente equivalen a "consenso".

21 Por ejemplo, en el campo de la prevención de los desastres mal llamados "naturales", todos los profesionales que intervengan en ella tendrán que construir un concepto integrado de "desastre" y determinar por qué no lo logran si esto ocurre. $\mathrm{O}$, más específicamente, un psicólogo tendrá que contar con conocimientos básicos acerca del origen y desarrollo de los fenómenos involucrados (por ej. terremotos, sequías, huracanes) porque sin ello no podrá comprender cómo amenazan o "agreden" a poblaciones concretas. propiamente profesionalizante se desagrega típicamente, con un estilo conservador que requiere hoy una revisión crítica, en grandes áreas (psicología educativa, psicología del trabajo, psicología clínica, psicología del deporte, etc.). No siempre, aparecen especialidades más delimitadas.

La pregunta que se desprende es la siguiente: ¿es inevitable que las referidas fragmentaciones generen en Psicología "nichos lingüísticos" (semánticos y semióticos) o discursos paralelos, perpetuamente incomunicados?

Me parece que la respuesta será diferente según cómo se entiendan nuestras necesidades de comunicación. Tal como sucede con los nexos interdisciplinarios, no parece sensato pretender que psicólogos insertos en determinadas líneas temáticas estén en capacidad de manejar "toda la teoría" y entender "toda la jerga" que se desarrolla en otras.

La cuestión radica en encontrar las relaciones de sentido necesarias para evitar que nuestros desacoplamientos teóricos no sean más que una mala costumbre, muchas veces condimentada por la tendencia a emplear alusiones mutuas que con frecuencia son sumamente simplistas o directamente caricaturescas.

Hay en todo esto una cuestión de fondo: si la Psicología no tuviera por lo menos una pregunta epistemológica en común, carecería de identidad disciplinar. El problema es que tales preguntas en común no pueden ser halladas con lentes diferentes y por lo mismo, pareciera que no podremos zafarnos de la intraducibilidad. Para evitar reiteraciones, se volverá sobre este tema más adelante.

\section{EL VERDADERO PROBLEMA: LA PARADIGMATITIS EN PSICOLOGÍA}

De pronto, aunque no recientemente, pareció abrirse en nuestro oficio una salida muy sensata para quienes percibían tintes divisionistas, sectarios o unidimensionantes en la noción de "paradigma": caracterizar a la Psicología como una ciencia "multiparadigmática". Expresión con trazas contundentes, tolerantes y aún más elegantes, que en todo caso no podría inspirarse en Kuhn, sino más bien en 
alguien que no valoró demasiado su pensamiento: Paul K. Feyeraben ${ }^{22}$.

Hace una década, M.Q. Patton fue más allá todavía al proponer que, además de los paradigmas principales, se reconozcan otros de rango inferior o "miniparadigmas".

A estas alturas, uno se siente tentado por la lógica formal: si no hay "un" paradigma en Psicología, ¿cómo puede haber varios? Por la misma ruta, no se les permitiría la entrada a términos como "antiparadigmático" o "postparadigmático". Pero no nos quedemos con una conclusión tan brusca.

Permítanme más bien recurrir a un grato recuerdo de mi infancia: una vez mis abuelos me llevaron al estadio provinciano a ver un partido de fútbol. Apenas terminado el primer tiempo, durante el cual guardó un inusual silencio, mi abuela, primeriza como espectadora de ese deporte, le preguntó a su esposo por qué no se le compraba un balón a cada uno de esos niños, en lugar de mortificarlos con incesantes carreras, puntapiés y empujones tras uno solo. Peor aún, añadió preocupada, ni el adulto vestido de negro, que no parecía en sus cabales al correr hacia atrás insistentemente, lograba apaciguar tan indecoroso espectáculo con sus pitazos incesantes.

Mi abuelo, tifosi consumado pero hombre paciente, le explicó que si cada niño manejara su propio balón y se prescindiera del hombre de negro, no estarían jugando fútbol.

No fue tan candorosa, por supuesto, pero al fin $y$ al cabo equivalente, una inquietud que, entre muchos otros, divisara el español J. Vicente Viqueira en un libro escrito durante la tercera década del siglo $\mathrm{xx}^{23}$ : ¿por qué en la

22 Véase: Feyerabend, Paul. "Cómo defender a la sociedad contra la ciencia". Cap. VIII de Revoluciones científicas (I. Hacking, comp. op.cit.). Este trabajo procede de Radical Philosophy, 1975. Se extrae la siguiente aseveración: "Las ideas de Kuhn son interesantes, pero ¡ay! son demasiado vagas para hacer surgir algo que no sea aire caliente".

23 Viqueira, Vicente J. Psicología Contemporánea. Ediciones Torre de Babel (Internet). Digitalización basada en la $2^{\text {a }}$. edición de esta obra. Editorial Labor, 1937. El autor fallecido en el año 1924, consideró que "una tendencia ecléctica, en el
Psicología no se ha concretado esa "resolución de las diversas oposiciones"?

Me parece que la pregunta es otra y tiene una vigencia permanente: ¿qué nos divide y por qué? Pero un mal severo recorre nuestras filas y prácticamente sepulta esa cuestión: el erróneo uso que se le da hoy en casa a la noción de paradigma, con sus correspondientes secuelas. Mal que, en su origen, poco o nada tiene que ver Kuhn o cualquier filósofo de la ciencia.

Con la venia de quien lee, llamaré a dicho mal paradigmatitis. Emplearé semejante palabreja para referirme a esa situación, que puede llegar a inundar escuelas o facultades universitarias, en que:

el concepto de "paradigmas" se adopta para motejar, erróneamente, corrientes de pensamiento que supuestamente no se tocarían en su desarrollo o cuyos verdaderos puntos de fricción no son dilucidados en sus razones de fondo, interpretándose como luchas de poder mal definidas o como simples pugnas competitivas entre grupos profesionales ${ }^{24}$.

En Psicología — pienso que esto es válido para todas las ciencias sociales - no hay una pluralidad de corrientes aisladas o aislables, con derecho a ignorarse mutuamente o a reducir la búsqueda de su propia hegemonía a estratagemas de poder ${ }^{25}$, sino "corrientes de pensamiento que coexisten dialécticamente".

La instalación sectaria sobre caricaturas o exorcismos lleva a una pseudoepistemología con tijeras, a una "automutilación cognoscitiva", que se arrima mucho más al pensamiento mágico que a un debate teórico serio: no existe o no vale la pena tomar en cuenta lo que deliberadamente ignoro porque no me gusta.

La idea de coexistencia diálectica se refiere a que "la disciplina contiene posturas

buen sentido del término" se hacía notar "cada día con mayor fuerza y frecuencia" en la "ciencia del alma”.

24 No estará de más reiterar que poco o nada tiene que ver Kuhn en todo esto.

25 Sería un alarde romántico pensar en la posibilidad de que no las hubiese del todo. 
ideológico-epistemológicas diversas, entre las cuales se entablan contradicciones de fondo, entrecruces, aproximaciones y reemplazos que configuran el núcleo dinámico de su movimiento teórico".

Es necesario comprender, adicionalmente, que cuando una corriente de pensamiento afirma su superioridad sobre otra y sobre todo, cuando lo hace de una manera intensa o agresiva, inevitablemente se transforma a sí misma. Así, por ejemplo, cuando el conductismo radical tomó los principios comtianos para presentar al psicoanálisis como un retorno a la metafísica, se vio ante el imperativo de revisar y defender sus propias reglas, en respaldo de su particular concepción de cientificidad. A la inversa, el psicoanálisis no podría simplemente ignorar las críticas que le atribuyen una afición desmedida a la palabrería como demostración palmaria de su falta de rigor científico.

La peor y más radical secuela de la paradigmatitis consiste en que, al fomentar la actividad desconectada de tendencias de pensamiento, se genera una visión deformada de la Psicología. Si la propuesta futbolera de mi abuela se hubiese concretado, no existiría el fútbol. Si no tuviésemos más que una colección de "paradigmas", no seríamos una disciplina.

Por si se percibieran señales "eclecticistas" en lo que vengo diciendo, me apresuro a negarlas categóricamente: la ciencia no es solamente un ejercicio racional, en que las dificultades de comunicación se originen simplemente a partir de diferencias semánticas o epistemológicas, porque lo que se busca y se produce con ella incide en la transformación de la realidad humana y por eso moviliza compromisos e intereses ${ }^{26}$.

26 Aunque estos temas no suelen despertar mucho interés en la actualidad, sigue siendo importante comprender los amarres ideológicos que se dieron en el surgimiento del positivismo y el materialismo dialéctico durante el siglo XIX. Hubo positivismos anteriores a Comte, pero el positivismo comtiano alcanzó su rápida influencia sobre ciertos pilares de la ideología de la burguesía como clase dominante en ascenso: su rechazo a la metafísica armonizaba con el propósito del nuevo poder, en cuanto a superar un modo de pensar que se visualizaba como prototípico del Antiguo Régimen, su dogma
Si por "ideología" entendemos "toma de posición" ante lo que conocemos y sus posibles transformaciones, las ciencias sociales son intrínsecamente ideológicas. Lo cual hace ilusorio pensar que nuestras discusiones puedan ser pura y fríamente "epistemológicas": siempre estarán de por medio cuestiones enclavadas en las consecuencias de nuestro quehacer. Se trata de identificar las verdaderas contradicciones que protagonizamos $y$ discutir sus consecuencias sobre nuestros actos $y$ valores. ;En eso consiste el pluralismo universitario, no en darle cuerda a trozos incomunicados de ideas y responsabilidades!

Pero las cosas no terminan allí. La visión adulterada de la Psicología como un archipiélago cuyas islas, según el momento, se lanzan obuses dogmáticos o cultivan relaciones turísticas, es el caldo de cultivo al menos para:

a) Enfoques dogmáticos que nos alejan del debate productivo. Más aún, terminan por privarlo de sentido: "¿si toda la verdad está en mi casa, a cuento de qué voy a discutir mis ideas con los vecinos?".

b) El florecimiento de posturas ultracientificistas, que justifican sus desplantes hegemónicos mediante una nueva versión del espejo mágico de la madrastra (La Cenicienta): "Dime espejito, cuál es en Psicología la manera de investigar que se encuentra más cerca de las ciencias duras... La nuestra ¿verdad?”.

Mal encaminados van los ardores cientificistas cuando se trata de reclamar su reinado. La Psicología es una ciencia, pero no en la definición más canónica y finalmente desértica

del progreso confirmaba el papel de la burguesía en la demolición de un absolutismo estancado y posiblemente, lo más importante, su adhesión a lo observable proporcionó un buen punto de apoyo a esa clase para confiar en la verdad de las transformaciones que impulsaba: "es cierto lo que está pasando". En lo que respecta al materialismo dialéctico e histórico, la equivalencia entre lo observable y lo verdadero significaba confirmar la legitimidad del orden social que se denunciaba como alienante e injusto. De allí que su concepción acerca de lo observable como apariencia, cobre tanta importancia en su entramado filosófico. 
del término: su aprendizaje y práctica implican compromiso, sensibilidad, incertidumbres fecundas, contenidos estéticos y otras proyecciones dentro de la existencia humana. La pretensión de convertirla por completo en "ciencia dura" es un enorme despropósito, porque eso equivale a ignorar la riqueza multidimensional de su objeto de conocimiento y las particularidades que revisten sus modos de conocimiento.

Curiosamente, a veces se enlista en la nómina de paradigmas, a la psicobiología o sus versiones más actuales (como las neurociencias) o a la psicología social ${ }^{27}$. Se podría entender que la confusión alcanza con esto un punto máximo, porque con ella se intenta contraponer lo inseparable. Pero si se mira el asunto con más cuidado, se notará que tiene tras de sí lo que en Psicología se ha denominado "tesis de las dos culturas", según la cual el desarrollo de esta disciplina se ha caracterizado desde sus inicios por la coexistencia de dos concepciones -la "cientificista" y la "comprensivo-hermenéutica" - que han configurado en ella paradigmas excluyentes (en el sentido kuhniano) y cuyas divergencias explican su crisis permanente (Cornejo, 2005).

Cualquiera que sea el plano en que situemos esta cuestión, el verdadero problema no consiste en describir la coexistencia de "dos culturas", sino en una sorprendente incapacidad para entender que la desagregación de dimensiones que son constitutivas del individuo concreto, con sus correspondientes consecuencias metodológicas, no puede dar lugar a su manejo como opciones en choque o mutuamente excluyentes.

c) Localizar donde no están las diferencias o contradicciones epistemológicas $e$ ideológicas. Hace años, un estudiante me abordó fuera de la clase y con cierto sigilo, me planteó más o menos lo

27 Me refiero a una posibilidad no imaginaria: la colocación de una determinada área de investigación en un lugar "preferencial" dentro de un centro universitario (que posiblemente sería una prioridad válida dentro de una planificación curricular equilibrada) puede dar lugar a luchas administrativas envueltas en argumentos "paradigmáticos". siguiente: "vea profe, a mí como que me cuadra eso del materialismo dialéctico, pero ocupo estadística en mi proyecto de tesis... ¿qué hago?”. Más claro no canta un gallo. Aquel joven había entendido que el método cuantitativo era "elegible" solamente desde una postura positivista. Su duda probablemente luciría hoy como un chihuahua en un concurso de gatos, pero no termino de agradecerle su pregunta. Hasta hoy me permite tener presente que nuestras contradicciones teóricas son de fondo, remiten a niveles ontoepistemológicos e ideológicos y por tal razón, el plano metodológico-técnico no es el lugar para buscarlas en primera instancia.

Es preciso que eliminemos de nuestros debates y prácticas los "desvaríos paradigmatoides", síntoma primario de paradigmatitis, por cuanto nos llevan a buscar donde no están las contradicciones teóricas. En lo que concierne a la enseñanza universitaria, flaco servicio les hacemos a los y las estudiantes si se cierran los espacios para preguntarse "cómo y por qué se originan $y$ desarrollan contradicciones radicales entre las corrientes o tendencias que van configurando la Psicología como disciplina”.

Siento una gran preocupación al ver a muchos estudiantes envueltos en las redes de una pugna en que se confunden las opciones. Piden que se respeten sus "afinidades paradigmáticas" como si se tratara de un derecho o licencia para mantener una visión fragmentada de la Psicología. Se colocan en la carrera, voluntariamente, como lectores de un solo libro.

Es necesario que el futuro psicólogo, ayudado por profesores que no actúen como catequistas monotemáticos, se interese en conocer los fundamentos de todas las corrientes de pensamiento que dinamizan a la disciplina. O sea, que tome posición entendiendo con claridad el origen $y$ alcances de las contradicciones en juego. Que no vea los cursos en que se tratan "esas otras materias" como un menú de restorán en un momento de mucho apetito, disponiéndose a escoger un guiso $y$ a ignorar los otros, porque entonces se estará encaminando hacia una seguridad ficticia. Hincha 0 
forofo sí, pero de la Psicología, sin olvidar que el campeonato se juega entre varios equipos $y$ que cada partido es una "síntesis dialéctica" de desempeños opuestos.

Ninguna verdad sólida, solo desatinos, alcanzamos al "paradigmatizarnos".

\section{BIBLIOGRAFÍA}

LIBROS

Chalmers, A. ¿Qué es esa cosa llamada ciencia? Buenos Aires: Siglo XxI de Argentina Editores, 2004.

Kuhn, Thomas (1964). "Una función para los experimentos mentales". Revoluciones científicas. Hacking, Ian (comp.). México: Breviarios del Fondo de Cultura Económica, 1985.

Kuhn, Thomas (1977). La tensión esencial. México: Fondo de Cultura Económica, 1982.

Piaget, Jean y García, Rolando. Psicogénesis e historia de la ciencia. México: Siglo XXI editores, 1982.

Putnam, Hilary. "La 'corroboración' de las teorías". Revoluciones científicas. Hacking, Ian (comp.). México: Breviarios del Fondo de Cultura Económica, 1985.

REVISTAS

Cornejo, Carlos. "Las dos culturas de/en la Psicología”. Rev. de Psicología de la Universidad de Chile XIV (2). Santiago, Chile. 2005.

\section{COMUNICACIONES EN INTERNET}

Brunetti, Juan y Ormart, Elizabeth. "El lugar de la Psicología en la epistemología de Kuhn: la posibilidad de una psicología de la investigación científica”. Rev. Cinta Moebio 38. Universidad de Chile, 2010: 110-121. En: $<w w w . m o e b i o . u c h i l e . c l / 38 /$ brunetti.html $>$ [Consultado en octubre de 2011].

Brunetti, Juan. "Acerca de los intereses del primer Kuhn sobre los procesos psico-cognitivos".
Revista Cuadernos de Materiales 23. 2011: 57-77. En: <http://www.filosofia. net/materiales/numero $23 \mathrm{~b} . \mathrm{html}>$ [Consultado en octubre de 2011].

Gabucio, Fernando. "El último Kuhn y la Psicología”. Anuario de Psicología 33 (2). Facultad de Psicología de la Universidad de Barcelona, 2002: 249266. En: <http://www.raco.cat/index. php/anuariopsicologia/issue/view/5141/ showToc $>$ [Consultado en octubre 2011].

Lorenzano, Pablo. "Inconmensurabilidad teórica y comparabilidad empírica: el caso de la genética clásica". Revista Análisis filosófico 28 (2). 2008: 239279. En: <http://www.scielo.org. ar/scielo.php?script $=$ sci_arttext $\&$ pid=S1851-96362008000200005> [Consultado en octubre de 2011].

Patton, M.Q. Qualitative evaluation and research methods. Newbury Park: Sage, 1990. En: <www.amazon.com>.

Vázquez, Alonso; Acevedo, José Antonio; Manassero, María Antonia y Acevedo, Pilar. "Cuatro 'paradigmas' básicos sobre la naturaleza de la ciencia". Rev. Argumentos de Razón Técnica 4. 2001: 135-176. En: <www.oei.salactsi/ acevedo20.htm>.

Viqueira, Vicente J. (1937). Psicología Contemporánea. Ediciones Torre de Babel. Digitalización basada en la $2^{\text {a }}$ edición de esta obra. Editorial Labor, 2007. En: < http://www.etorredebabel.com/Psicologia/PsicologiaContemporanea-Viqueira.htm > [Consultado en octubre de 2011].

Yela, Mariano. "La evolución del conductismo". Rev. Psicothema 8 (Suplemento 1). 1996: 165-186. En: < http://www.psicothema. com/psicothema.asp? id =657> [Consultado en octubre de 2011].

Fecha de ingreso: 25/01/2012 Fecha de aprobación: 15/06/2012 